\title{
Impact of some local organic by-products on Acheta domesticus growth and
}

\section{meal production}

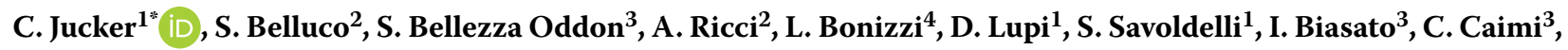 \\ A. Mascaretti ${ }^{5}$ and L. Gasco ${ }^{3}$ \\ ${ }^{1}$ Department of Food, Environmental and Nutritional Sciences, University of Milan, via Celoria 2, 20133 Milan, Italy; \\ ${ }^{2}$ Istituto Zooprofilattico Sperimentale delle Venezie, viale dell'Università, 10, 35020 Legnaro (PD), Italy; ${ }^{3}$ Department of \\ Agricultural, Forest and Food Sciences, University of Turin, L. go Braccini, 2, 10095 Grugliasco (TO), Italy; ${ }^{4}$ Department \\ of Biomedical, Surgical and Dental Sciences, University of Milan, via della Commenda 10, 20122 Milano, Italy; ${ }^{5}$ Centro \\ per lo Sviluppo Sostenibile, via Daverio 7, 20122 Milan, Italy; costanza.jucker@unimi.it
}

Received: 7 July 2021 / Accepted: 4 October 2021

(c) 2021 Wageningen Academic Publishers

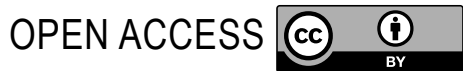

RESEARCH ARTICLE

\begin{abstract}
The house cricket Acheta domesticus is one of the species of major interest as alternative protein source for humans in the recent research of sustainable and nutritious sources of food. However, grain feeds, feed for poultry and soybean still represent common source of feeds for the insect industry. The aim of this study was to evaluate the influence of some agro-food by-products on the growth parameters of the crickets and the nutritional composition of the final cricket meal. Our study included five by-products (maize grain distiller, fruits and vegetables, grape marc, and two brewery's wastes), while hen feed was used as a control diet. Substrates were analysed for their microbiological contamination prior to be provided to crickets. No Listeria and Salmonella were detected, but high microbial counts were observed. Crickets grown on the given by-products showed significant differences on the insect's weight starting from the third week. High mortality was observed on all substrates, except on maize distiller and the control diet. The final cricket meal showed a similar protein content (66-68\% as is), while the lipid content was higher in the meal from cricket reared on maize distiller ( $22 \%$ as is). Finally, microbiological and chemical analyses on the cricket meals did not show safety concerns for the consumers. The by-products studied, except maize grain distiller, did not support an optimal cricket rearing, but more studies are necessary to identify a mix-formulation meeting the cricket nutritional requirements.
\end{abstract}

Keywords: house cricket, protein production, organic substrates, growth performance, microbiological characterisation

\section{Introduction}

In the recent framework of insect as sustainable protein source, Acheta domesticus L. (Orthoptera: Gryllidae), the house cricket, is one of the species of major interest for humans due to its high protein content, above $60 \%$ on a dry weight basis (Fernandez-Cassi, 2019; Van Huis, 2013). This species has been reared since years in many geographical areas as food for pets (in particular for reptiles and amphibians) and today represents one of the species (together with Gryllus bimaculatus and some Tenebrionidae as Tenebrio molitor) as edible insect for humans (EFSA, 2021a,b; Fernandez-Cassi, 2019;
Govorushko, 2019). The market of whole or powdered crickets over the last years has been growing due to the increased interest from the consumers as a more sustainable food (Jensen, and Lieberoth, 2019; Kulma et al., 2020; Laureati et al., 2016; Mancini et al., 2019; Pippinato et al., 2020). However, grain feeds, feed for poultry and soybean still represent common source of feeds for the insect industry. These ingredients are in competition with humans and animals, and contribute to increase the production costs, in addition to the environmental costs (Pastell et al., 2021). In fact, different studies considering the environmental impact of the mass rearing of edible insects have identified in the feeding substrate the highest 
environmental load on the production process (Lundy and Parrella, 2015; Smetana et al., 2016; Van Huis and Oonincx, 2017). Moreover, in European Countries insects intended as food and feed can only be fed with approved raw materials, i.e. materials of plant and/or animal origin compliant with the Regulation 2017/1017 (EU, 2017). Thus, over the last years, the attention on the exploitation of alternative feeding diets for the mass rearing of insects, formulated with by-products or organic-wastes, has grown. Agro-industrial by-products have been identified as a useful source of feed for different species of intensively famed insects (Galassi et al., 2021; Gasco et al., 2020; Jucker et al., 2019; Morales et al., 2020a,b). By-products are available in high quantity, low cost, often have a good nutritional profile and represent a waste for humans. In this way, they can greatly contribute to lower the environmental impact and the cost of insect production. Furthermore, the exploitation of these growing substrates by insects clearly represents a good example of circular economy process (Bava et al., 2019; Cappellozza et al., 2019; Fowles and Nansen, 2020; Pinotti et al., 2019). Several Authors evaluated different by-products of vegetable origin as growing substrate for $A$. domesticus focusing on growth rate, feeding preferences, biomass production and feed conversion index (Bawa et al., 2020; Harsányi et al., 2020; Lundy and Parrella, 2015; Morales-Ramos et al., 2020b; Oonincx et al., 2015; Pastell et al., 2021; Sorjonen et al., 2019). In addition, feeding substrate can influence the proximate composition of the cricket and, consequently, the nutritional quality of the cricket meal (Ssepuuya et al., 2021).

Moreover, although the use of agro-industrial by-products as a feeding substrate can contribute in reducing the environmental impact of insect mass-rearing, it might result into food safety risks (Ng'ang'a et al., 2021; Ordoñez-Araque and Egas-Montenegro, 2021). Therefore, it is necessary to assess the food safety of the use of by-products as feed and of the produced product (e.g. insect meal).

In order to identify low cost and sustainable alternative feeds for the house cricket rearing, the objective of the current study was to evaluate the feasibility of using some organic by-products.

To identify the optimal rearing substrates, the following characteristics were selected as eligible criteria: by-products from the agri-food industry, plant origin, microbiological safety, not in competition with human protein sources, availability in local food chains. Brewery waste, grape marc, maize grain distiller, fruits and vegetables were selected as growing substrates and the following aspects were investigated: (1) nutritional composition; (2) chemical and microbiological quality; (3) influence of substrate on the insect performance, in terms of growth, mean body weight, survival and bioconversion ability; (4) influence of the diet on the nutritional, chemical and microbiological properties of the house cricket meal.

\section{Materials and methods}

\section{Substrates}

Different organic by-products were collected from local industries derived from agro-food industries production. The following by-products were tested as feeding diet: brewery's waste (trub or brewery' spent grains), maize grain distiller (MD), fruit and vegetables (apple, pear and zucchini in equal weight) (FV) and a by-product from wine production (grape marc (GM)). Moreover, a laying hen diet (Sani sapori, Petrini) (HF) was used as a control diet. Brewery' spent grains (BG) were tested alone or mixed with trub (50:50) (BG+TRUB). Grape marc was also tested alone or added with hen diet (30:70) $(\mathrm{GM}+\mathrm{HF})$. Substrates were given to the crickets as they were, without having been processed except trub that was dehydrated before being provided due to its high moisture content.

\section{By-product and cricket meal analyses}

Experimental substrates and cricket meals were analysed to assess their chemical composition.

Organic by-products and hen diet were ground using a cutting mill (MLI 204; Bühler AG, Uzwil, Switzerland). They were than analysed for dry matter (DM, \#934.1), ash (\#984.13) and crude protein (CP, \#984.11) according to AOAC International (2000) and ether extract (EE, \#2003.05) following AOAC International (2003). Nitrogen free extract (NFE) was calculated as: DM-(CP+EE+ash).

At the end of the growing trail, samples of cricket meal were analysed for their proximate composition as described above. To obtain the crude protein content, the nitrogen to protein conversion factors of 6.25 and of 4.76 were used for substrates and cricket meal (Janssen et al., 2017), respectively.

\section{Cricket colony}

The four-days old crickets used for the trials were obtained from the house cricket colony present at the University of Milan in a climatic room $\left(27 \pm 1^{\circ} \mathrm{C}, 60 \pm 5 \% \mathrm{RH}\right.$ and L:D 12:12). A. domesticus adults were reared inside plastic containers $(71 \times 46 \times 35 \mathrm{~cm})$ provided with 30 -eggs cardboard $(25 \times 40 \mathrm{~cm})$ in order to ensure a sufficient surface area available for the crickets to prevent cannibalism. Inside each box, water and food (hen feed, previously described) were supplied ad libitum. Water was supplied by one chicken water feeder in each container. Oviposition sites consisted of plastic containers $(15 \mathrm{~cm}$ diameter) filled with moistened peat and were added into adult containers for 
female oviposition. Every three days, containers with eggs were removed and positioned in a climate room at $28 \pm 1{ }^{\circ} \mathrm{C}$, $60 \pm 5 \% \mathrm{RH}$ for egg hatching. When new-born pins appeared, water, hen feed and egg cardboards were added.

\section{Growth, survival, bioconversion and meal production}

Each experimental container $(71 \times 46 \times 35 \mathrm{~cm})$ consisted of 1000 four-days old crickets (number of samples estimated on the basis of the weight carried out on a subsample of 100 neanids). For each rearing substrate three replicates were set up. In each container, 30-egg cardboards were added to increase the space for the crickets. Water was always available and provided with a drinking trough for chicken. Crickets were checked daily and experimental diets were given ad libitum, providing new feed when it had been consumed avoiding starvation. The amount of fresh food added was always recorded.

To assess the insect growth, 50 individuals randomly chosen from each experimental container were weighed weekly from the beginning of the trial with an analytical scale (Orma BCA200S, Milan, Italy; $0.1 \mathrm{mg}$ ). As the measure was not destructive, after weighing, crickets were replaced in their respective container. The trial was ended when crickets had reached a harvestable size for meal production or when most part of the crickets were dead. Crickets were fasted for 24 hours, then they were collected from each container and weighted to obtain the final biomass yield.

The following performance parameters were calculated:

Biomass weight gain $(B W G, g)=\frac{\text { weight of cricket biomass yield at the end of the trial }(\mathrm{g})}{\text { weight of crickets at the beginning of the trial }(\mathrm{g})}$

Ingested food $(\mathrm{g})=\frac{\text { feed provided }(\mathrm{g})}{\text { residual feed at the end of the trial }(\mathrm{g})}$

Food conversion efficiency $(\mathrm{FCE})=\frac{\mathrm{BWG}(\mathrm{g})}{\text { ingested food }(\mathrm{g})}$

As we intended to produce cricket meal, crickets were rinsed with water in order to eliminate faeces and wastes, and killed by blanching $\left(1 \mathrm{~min}\right.$ at $100{ }^{\circ} \mathrm{C}$ in boiling water). After being counted to assess the survival in each experimental trial, they were dehydrated $\left(50^{\circ} \mathrm{C}\right.$ until a constant weight) and grounded (Hawos, Queen 2, Bad Homburg, Germany) to obtain the meal.

Cricket meals were kept under vacuum and stored in a refrigerator $\left(-18{ }^{\circ} \mathrm{C}\right)$ before being analysed for their nutritional characteristics.

\section{Microbiological analyses}

All microbiological analyses on substrate and/or cricket meal were carried out according to the following methods. Presence of Salmonella spp. was assessed through real time PCR according to validated standards (AFNOR BRD
07/06 - 07/04). Briefly, after pre-enrichment in sterile buffered peptone water for $24 \mathrm{~h}$, DNA was extracted through 'iQCheck SalmonellaTM II kit' (Bio-Rad, Segrate, Italy) according to manufacturer instructions and rPCR was run with CFX96 deep well thermocycler (BioRad). Presence of Listeria monocytogenes was assessed through real time PCR according to validated standards (AFNOR BRD 07/10 - 04/05). Briefly, after pre-enrichment in sterile LSB broth (Biorad) for 24 h, DNA was extracted through 'iQCheck Listeria ${ }^{\mathrm{im}}$. II kit' (Bio-Rad) according to manufacturer instructions and rPCR was run with CFX96 deep well thermocycler (BioRad).

The other microorganisms were counted through traditional microbiological methods. The samples $(20 \mathrm{~g})$ were diluted in $180 \mathrm{ml}$ of triptone solution and stomached for 1 minute before serial dilution. Enumeration of different microbial targets was carried out with the following methods. Aerobic mesophilic micro-organisms were enumerated by a total viable count. Bacterial suspensions were plated in melted liquid plate count agar, incubated at $30 \pm 1{ }^{\circ} \mathrm{C}$ for $72 \mathrm{~h}$ (ISO 4833-1:2013). Enterobacteriaceae were enumerated in pour-plates of violet red bile glucose medium with an overlay of the same medium and incubated at $37 \pm 1{ }^{\circ} \mathrm{C}$ for 24 h (ISO 21528-2:2017). Escherichia coli $\beta$-glucuronidase positive was enumerated after plating in melted tryptone bile glucuronide agar and incubation for $18-24 \mathrm{~h}$ at $44 \pm 1{ }^{\circ} \mathrm{C}$ (ISO 16649-2:2001). Staphylococcus aureus was enumerated after plating bacterial suspension in Baird Parker + melted rabbit plasma fibrinogen and incubated for 18-24 h at $37 \pm 1^{\circ} \mathrm{C}$ (ISO 6888-2:1999 / Amd 1 2003). Bacillus cereus was enumerated after $18-24 \mathrm{~h}$ of incubation at $30 \pm 1{ }^{\circ} \mathrm{C}$ in mannitol egg yolk polymyxin agar (ISO 7932:2004).

Clostridia sulphite-reducing were enumerated in sulphite agar after incubation for $24-48 \mathrm{~h}$ at $37 \pm 1{ }^{\circ} \mathrm{C}$, colonies were confirmed through Gram coloration and absence of growth in blood agar (ISO 15213:2003). Mould and yeasts were enumerated in Rose Bengal chloramphenicol agar after 3-5 days of incubation at $25 \pm 1{ }^{\circ} \mathrm{C}$ (Internal method BAT 016 2016). $\mathrm{pH}$ was measured with $\mathrm{pH}$ meter (Aqualab, 4TE; Aqualab, Meter Italia spa, Concordia Sulla Secchia (MO), Italy). Samples at room temperature were homogenised with $1 \times$ of distilled water and analysed (MFHPB-03:2014). Aw was measured with Aqualab Decagon Devices, Inc. Sample measurement was carried out after appropriate calibration with standard samples (ISO 18787:2017).

\section{Heavy metal quantification}

The quantification of metals $(\mathrm{Pb}, \mathrm{Cd}, \mathrm{As})$ in obtained cricket meals was carried out through ICP-MS Cap-Q Thermo Fisher equipped with software Qtegra, vacuum system, and chiller (ThermoFlex2500; Thermo Fisher Scientific, Monza (MI), Italy). Briefly, 1 gram of samples was homogenised in liner Xpress, added with $8 \mathrm{ml}$ of $\mathrm{HNO}_{3}$ and $2 \mathrm{ml}$ of $\mathrm{H}_{2} \mathrm{O}_{2}$, 
assembled in liner express and digested through microwave mineralisation (Ethos, Milestone, Sorisole (BG), Italy).

\section{Statistical analysis}

One way-ANOVA was used to assess the influence of the different rearing substrates on the following parameters: final weight, survival, biomass production and food conversion efficiency. The Tukey-Kramer honestly significant difference multiple comparisons test was performed for mean separation. Prior to analyses, all data were examined with Levene's test for homogeneity of variance and with the ShapiroWilk test for normal distribution. The results are expressed as mean and pooled standard error of the mean. Significance was declared at $P \leq 0.05$. Data were elaborated with SPSS for Windows statistical package, Version 25.0 (SPSS Inc., Chicago, IL, USA).

\section{Results}

\section{Characterisation of the experimental substrates}

The proximate composition of the organic by-products and HF is reported in Table 1. As FV was used 'as is', it showed the lowest dry matter and nutrient content. Among substrates having a DM higher than $80 \%$, the protein content was comprised between a minimum of 10.65 as is in GM to a maximum of $29.88 \%$ as is in BG+TRUB. The lowest EE content was observed in GM (2.41\% as is), while the highest in MD (8.73\% as is). With the exception of FV which reported a NFE content of $8.62 \%$ as is, in all substrates NFE was close or higher than $50 \%$, with the highest value reported for BG substrate (61.33 as is).

The results of microbiological analyses of different raw materials and HF supplied to insects during farming are reported in Table 2. Listeria and Salmonella were never isolated in the tested samples. Results show high total microbial counts, in particular for GM (6.9 log cfu/g) and BG (5.4 log cfu/g). E. coli, S. aureus and sulphite reducing Clostridium were not detected. Moulds were always detected with counts up to $5.2 \log \mathrm{cfu} / \mathrm{g}$ (GM), whereas yeasts were detected in trub. Presumptive B. cereus was detected in Trub, HF and GM.

\section{Influence of substrates on cricket growth and survival}

The growth of $A$. domesticus was observed on all the growing substrates, but with significant differences in terms of development days, weight reached, and survival rate. Table 3 reports the cricket mean weight at each sampling week. Statistical differences in the weight of the crickets

Table 1. Proximate composition (\% as is) of organic by-products used as rearing substrates for the Acheta domesticus. ${ }^{1}$

\begin{tabular}{|c|c|c|c|c|c|}
\hline & DM & $\mathrm{CP}$ & EE & NFE & Ash \\
\hline$B G$ & $94.66 \pm 0.05$ & $22.31 \pm 0.04$ & $6.18 \pm 0.04$ & $61.33 \pm 0.02$ & $4.84 \pm 0.00$ \\
\hline$B G+T R U B$ & $93.69 \pm 0.04$ & $29.88 \pm 0.12$ & $5.87 \pm 0.03$ & $52.65 \pm 0.13$ & $5.29 \pm 0.01$ \\
\hline FV & $10.53 \pm 0.03$ & $1.20 \pm 0.02$ & $0.20 \pm 0.01$ & $8.62 \pm 0.07$ & $0.51 \pm 0.00$ \\
\hline GM & $84.21 \pm 0.06$ & $10.65 \pm 0.06$ & $2.41 \pm 0.09$ & $60.34 \pm 0.14$ & $10.80 \pm 0.05$ \\
\hline $\mathrm{GM}+\mathrm{HF}$ & $85.55 \pm 0.06$ & $12.27 \pm 0.10$ & $2.95 \pm 0.07$ & $58.20 \pm 0.11$ & $12.14 \pm 0.02$ \\
\hline MD & $89.00 \pm 0.10$ & $26.31 \pm 0.12$ & $8.74 \pm 0.08$ & $49.88 \pm 0.09$ & $4.07 \pm 0.01$ \\
\hline HF & $88.86 \pm 0.06$ & $16.03 \pm 0.22$ & $4.12 \pm 0.03$ & $53.22 \pm 0.12$ & $15.26 \pm 0.06$ \\
\hline
\end{tabular}

${ }^{1} \mathrm{BG}=$ brewers' grain; $\mathrm{CP}=$ crude protein; $\mathrm{DM}=$ dry matter; $\mathrm{EE}=$ ether extract; $\mathrm{FV}=$ fruit and vegetable; $\mathrm{GM}=$ grape marc; $\mathrm{HF}=$ hen feed (control); $\mathrm{MD}=$ maize distiller; NFC = nitrogen free extract; NFE = DM $-(C P+E E+a s h)$.

Table 2. Results (log cfu/g) of microbiological analyses of the experimental substrates. ${ }^{1}$

$\begin{array}{lllllll}\text { Substrate } & \text { TMC } & \text { Moulds } & \text { Yeasts } & \begin{array}{l}\text { Escherichia coli } \\ \text { B-glucuronidase }\end{array} & \begin{array}{l}\text { Staphylococcus } \\ \text { coagulase + }\end{array} & \text { Bacillus cereus } \\ \text { Clostridium SR }\end{array}$

${ }^{1} \mathrm{BG}=$ brewers' grain; $\mathrm{GM}=$ grape marc; $\mathrm{HF}=$ hen feed (control); $\mathrm{MD}=$ maize distiller; $\mathrm{SR}$ = sulphite reducing; $\mathrm{TMC}$ = total microbial counts. 
were noticed only starting from the third week, with lightest weights on $\mathrm{GM}$ and $\mathrm{BG}\left(\mathrm{F}_{6,14}=5.54 ; P<0.05\right)$. Crickets fed with hen diet always differed from others with higher values; from week six also crickets provided with MD reached a weight similar to HF cricket. All other substrates gave lighter individuals at each sampling dates.

Harvestable crickets were collected at week 7 on HF, week 8 on MD and week 9 on GM+HF and weighted. The quantity of collected adults on GM+HF was not sufficient to produce meal. On BG all crickets died after 4 weeks, on GM after 7 weeks, on the BG+TRUB after 8 weeks, while on FV last samples were collected after 9 weeks; on these substrates, only few specimens reached the adult stage and were weighted. Final cricket weight (mean individual weight) ranged between a minimum of $0.0018 \mathrm{~g}$ on GM to a maximum of $0.387 \mathrm{~g}$ reached on $\mathrm{GM}+\mathrm{HF}$. The final weight significantly differed among the substrates $\left(\mathrm{F}_{6,14}=121.76\right.$; $P<0.05)$ : highest weights were observed in adults fed on $\mathrm{HF}, \mathrm{MD}$ and the mixture GM+HF. Final weights where the lowest in samples grown on BG, GM, while they showed intermediate values when reared on the mixture of BG+TRUB or on FV.

Survival of $A$. domesticus differed significantly among the experimental substrates tested $\left(\mathrm{F}_{6,14}=31.38 ; P<0.05\right)$ (Table $4)$. The highest survival was observed on $\mathrm{MD}(55.8 \pm 10.60 \%)$ and $\mathrm{HF}(52.6 \pm 3.77 \%)$ substrates, showing no statistical differences, while on the other diets only a maximum of $8.2 \pm 1.96 \%$ of survival on FV was assessed. These results strongly impacted the final cricket biomass and meal production.

\section{Cricket yield and meal production}

Yield cricket was calculated as the weight of the crickets collected at the end of each trial. A. domesticus was not collected on GM and BG due to the high mortality. On the other experimental substrates, the yield of $A$. domesticus varied greatly $\left(\mathrm{F}_{4,10}=68.168 ; P<0.05\right)$. The mean highest yield was reported on HF $(181 \pm 22.95 \mathrm{~g}$, fresh weight), followed by MD (151.90 $\pm 18.74 \mathrm{~g}$, fresh weight) (Table 4$)$. On the

Table 3. Cricket mean weight $(\mathrm{g})$ at each sampling week. .,2 $^{1,2}$

\begin{tabular}{|c|c|c|c|c|c|c|c|c|c|}
\hline \multirow[t]{2}{*}{ Week } & \multicolumn{9}{|c|}{ Substrates } \\
\hline & BG & BG+TRUB & FV & GM & $\mathrm{GM}+\mathrm{HF}$ & MD & HF & SEM & $P$-value \\
\hline 1 & 0.003 & 0.016 & 0.002 & 0.001 & 0.001 & 0.021 & 0.02 & 0.003 & 0.549 \\
\hline 2 & 0.003 & 0.020 & 0.006 & 0.004 & 0.005 & 0.024 & 0.009 & 0.003 & 0.544 \\
\hline 3 & $0.004 \mathrm{a}$ & $0.046 \mathrm{~b}$ & $0.012 \mathrm{ab}$ & $0.002 a$ & $0.016 a$ & $0.035 a b$ & $0.030 \mathrm{ab}$ & 0.004 & $<0.005$ \\
\hline 4 & $0.009 a b$ & $0.063 d$ & $0.021 a b c$ & $0.005 a$ & $0.041 \mathrm{bcd}$ & $0.057 \mathrm{~cd}$ & $0.232 \mathrm{e}$ & 0.016 & $<0.001$ \\
\hline 5 & - & $0.115 c$ & $0.040 a b$ & $0.007 \mathrm{a}$ & $0.098 \mathrm{bc}$ & $0.078 \mathrm{bc}$ & $0.214 \mathrm{~d}$ & 0.017 & $<0.001$ \\
\hline 6 & - & $0.133 b c$ & $0.054 a b$ & $0.004 a$ & $0.175 \mathrm{~cd}$ & $0.102 b c$ & $0.320 \mathrm{~d}$ & 0.025 & $<0.001$ \\
\hline 7 & - & $0.203 c$ & $0.087 b$ & $0.002 a$ & $0.240 \mathrm{c}$ & $0.271 \mathrm{~cd}$ & $0.313 d$ & 0.027 & $<0.001$ \\
\hline 8 & - & $0.207 b$ & $0.104 \mathrm{a}$ & - & $0.350 \mathrm{c}$ & $0.318 \mathrm{~cd}$ & - & 0.030 & $<0.001$ \\
\hline 9 & - & - & $0.125 \mathrm{a}$ & - & $0.387 \mathrm{~b}$ & - & - & 0.016 & $<0.001$ \\
\hline
\end{tabular}

${ }^{1} \mathrm{BG}=$ brewers' grain; $\mathrm{FV}=$ fruit and vegetable; $\mathrm{GM}=$ grape marc; $\mathrm{HF}=$ hen feed (control); $\mathrm{MD}=$ maize distiller.

${ }^{2}$ Means with different letters within the same row differ significantly $(P<0.05)$.

Table 4. Survival, cricket yield ( $g$, wet weight), cricket meal $(\mathrm{g})$ and food conversion efficiency observed on the cricket reared on the different substrates. ${ }^{1,2}$

\begin{tabular}{llllllllll} 
& BG & BG+TRUB & FV & GM & GM+HF & MD & HF & SEM & P-value \\
& & & & & & & & & \\
Survival (\%) & $1.47 \mathrm{a}$ & $5.30 \mathrm{a}$ & $8.20 \mathrm{a}$ & $0.83 \mathrm{a}$ & $7.73 \mathrm{a}$ & $55.80 \mathrm{~b}$ & $52.60 \mathrm{~b}$ & 5.22 & 0.001 \\
Cricket yield (g, wet weight) & - & $14.25 \mathrm{a}$ & $9.93 \mathrm{a}$ & - & $17.13 \mathrm{a}$ & $151.90 \mathrm{~b}$ & $181.00 \mathrm{~b}$ & 20.77 & 0.001 \\
Cricket meal (g) & - & $3.66 \mathrm{a}$ & $2.36 \mathrm{a}$ & - & $8.99 \mathrm{a}$ & $34.17 \mathrm{~b}$ & $45.57 \mathrm{c}$ & 4.79 & 0.001 \\
Food conversion efficiency & - & $0.11 \mathrm{a}$ & $0.01 \mathrm{a}$ & - & $0.07 \mathrm{a}$ & $0.54 \mathrm{~b}$ & $0.66 \mathrm{~b}$ & 0.07 & 0.001 \\
\hline
\end{tabular}

${ }^{1} \mathrm{BG}=$ brewers grain; $\mathrm{FV}=$ fruit and vegetable; $\mathrm{GM}=$ grape marc; $\mathrm{HF}=$ hen feed (control); $\mathrm{MD}=$ maize distiller.

${ }^{2}$ Means with different letters within the same row differ significantly $(P<0.05)$. 
other substrates the mean yield was statistically similar and reached a maximum of $17.13 \pm 2.22 \mathrm{~g}$ on $\mathrm{GM}+\mathrm{HF}$. The production of cricket meal followed the same trend as the biomass, with a maximum of meal on HF $(45.56 \pm 4.71 \mathrm{~g})$, followed by $\mathrm{MD}(34.17 \pm 2.29 \mathrm{~g})$. Only $8.99 \pm 0.77 \mathrm{~g}$ of meal were obtained from GM+HF feed, and even less grams on BG+TRUB (3.66 $\pm 0.49 \mathrm{~g})$ and FV $(2.36 \pm 0.28 \mathrm{~g})$. This amount of meal was insufficient for laboratory analysis, which were thus conducted only on HF and MD cricket meals.

\section{Bioconversion}

FCE observed on crickets reared on the different byproducts is illustrated in Table 4. A maximum value of $0.66 \pm 0.99$ was observed on HF. Only cricket reared on MD showed similar results to the HF, while on all other substrates the conversion efficiency was lower due to the high mortality observed during the experimental trial. Data are expressed on fresh weight basis.

\section{Analyses of cricket meal}

As previously described, a high mortality was recorded in some treatments and this did not allow to have enough cricket for meal production and chemical analyses. Therefore, proximate analyses were performed only on meal from MD and HF (Table 5). No statistical differences were reported for the different parameters.

Table 6 reports the results of the microbiological and heavy metal analysis conducted on the cricket powder. Cricket powder showed high counts of moulds and yeasts, whereas bacteria were present in lower counts, with the exception of TMC. Salmonella and Listeria were absent and S. aureus, $B$. cereus and Sulphite reducing clostridia where below $1 \log \mathrm{cfu} / \mathrm{g}$. As regards lead, cadmium and arsenic, results in the analysed cricket meals showed a low content for all the heavy metals. In particular, lead reached $0.25 \mathrm{mg} / \mathrm{kg}$ in MD cricket meal, while on HF meal was $0.09 \mathrm{mg} / \mathrm{kg}$. Cadmium and arsenic were always below $0.02 \mathrm{mg} / \mathrm{kg}$.

Table 5. Proximate composition ( $\%$ as is) of cricket reared on maize distiller (MD) and hen feed diet (HF) (n=3). ${ }^{1}$

\begin{tabular}{lrrrr} 
& MD & HF & SEM & $P$-value \\
& & & & \\
DM & 96.17 & 95.52 & 0.206 & 0.200 \\
CP & 66.49 & 68.56 & 0.691 & 0.200 \\
EE & 21.40 & 15.66 & 0.562 & 0.100 \\
Ash & 4.67 & 5.45 & 0.158 & 0.100 \\
\hline
\end{tabular}

${ }^{1} \mathrm{CP}=$ crude protein; $\mathrm{DM}=$ dry matter; $\mathrm{EE}$ = ether extract.
Table 6. Microbiological analysis and heavy metal presence $(\mathrm{mg} / \mathrm{kg})$ on the cricket meal on maize distiller (MD) and hen feed diet (HF). ${ }^{1}$

\begin{tabular}{lcc} 
& MD & HF \\
Microbiological analysis & & \\
Aw & $<0.25$ & - \\
TMC & 5.6 & 4.1 \\
Moulds & 3.0 & 2.7 \\
Yeasts & 3.3 & 2.5 \\
Escherichia coli ß-glucuronidase & $<1$ & $<1$ \\
Staphylococcus coagulase + & $<1$ & $<1$ \\
Bacillus cereus & $<1$ & 1 \\
Clostridium SR & $<1$ & $<1$ \\
Heavy metal presence & & \\
Pb & 0.25 & 0.09 \\
Cd & $<0.005$ & 0.02 \\
As & 0.02 & 0.02 \\
\hline
\end{tabular}

${ }^{1} \mathrm{Aw}=$ water activity; $\mathrm{SR}=$ sulphite reducing; $\mathrm{TMC}=$ total microbial counts.

\section{Discussion}

The present study aimed to highlight the influence of some vegetable by-products on the $A$. domesticus growth performance and on the nutritional composition of the final cricket meal. Exploitation of low-impact ingredient as cricket diet is indeed crucial to produce edible insects in a sustainable and cost-effective way. Different agro-industrial by-products of plant origin were chosen from the local agro-food industry and tested unprocessed (except trub) in order to reduce the costs of the rearing diet. However, as the growing substrate strongly influences the insect growth, is essential to identify suitable diets that guarantee, in addition to an economic and environmental saving, an optimal growth and maximisation of the yield of the insect produced.

Experimental by-products strongly influenced cricket survival rate and growth performance. Cricket survival rate was the main issue of this study. The cricket mortality on HF was comparable with the percentage observed by Morales-Ramos et al. (2020b) and Oonincx et al. (2015). High mortality registered on the tested by-products was comparable with Lundy and Parrella (2015) rearing crickets on food waste and crop residue and by Oonincx et al. (2015) on different by-products of plant origin. Only on $\mathrm{MD}$ crickets reached a survival rate comparable to the control diet (HF) and higher than other by-products tested also by other Authors. The high mortality observed could be attributed to the use of 4-days-old nymphs that are less resistant than the older and to the cannibalism which it is known to occur in particular among nymphs 
(Alexander and Otte, 1967; Collavo et al., 2005; Kieruzel and Chmurzynski, 1987; Patton, 1967). In fact, only few dead specimens were observed on the bottom of the experimental boxes, suggesting that more active nymphs supplemented their diet by feeding on their companions. Simpson et al. (2006) observed that crickets become cannibalistic when nutritional resources were limited. In particular, they observed that protein and salt were the key limiting resources in the Mormon cricket bands Anabrus simplex (Orthoptera: Tettigoniidae). In our study, salt presence was not considered, while the protein content of the experimental substrates was analysed; however, the cricket survival did not appear to be correlated with the protein content of the feeding substrates, been higher on MD and HF which were not the highest in protein content. It will be necessary to deepen the knowledge about the behaviour of cannibalism in A. domesticus in relation to the feed provided: only well-balanced nutritious diets with a high acceptability can allow to increase the survival reducing the cannibalism and, consequently, the mortality of the crickets.

Among the raw-ingredients tested, MD gave best results, comparable to the control diet, represented by HF. Adult final weight was similar to other studies where crickets were reared on vegetables substrates as in Morales et al. $(2018,2020 b)$ and Sorjonen et al. (2019). On this substrate, also the biomass collected was comparable to the results obtained on the control diet.

Mixing two ingredients, as with grape marc and hen feed $(\mathrm{GM}+\mathrm{HF})$, increased the final weight reached by adults. However, it has to be stressed that this treatment faced a high mortality $(92.23 \pm 0.67 \%)$ and the total biomass collected was low $(17.13 \pm 2.21 \mathrm{~g})$. Moreover, we noticed that specimens were able to select the preferred ingredient, feeding mostly on HF and leaving GM as waste. This behaviour was already observed by Patton (1967) and confirmed by MoralesRamos et al. (2020b) who demonstrated the self-selection for some ingredients by the crickets. We can therefore speculate that the high final weight reached by crickets fed GM+HF, could be due to a high feed availability for the low number of crickets that preferably ate the chicken feed that was also the treatment that, as single ingredient, led to the highest yield.

None of the specimen collected on BG and GM alone reached the harvestable size indicating that these substrates, as are, were not suitable for cricket rearing. The chemical composition of the substrate is known to influence different growing parameters. When not well balanced with other nutrients, either low or high protein content could delay the development time and results in lower individual biomass gained (Oonincx et al., 2015; Patton, 1967). Our results only partially agreed with this statement. Indeed, if the crude protein content of the GM substrate could be considered as low (10.65\%), the one of BG (22.31\%) cannot. Similarly, it was reported that the non-structural carbohydrate content has a positive effect on cricket biomass production, while fat content has a significant negative influence (MoralesRamos et al., 2020b). In our trial, both GM and BG were characterised by a high NFE content. We could argue that these substrates contained a high level of fibre, known to be indigestible by crickets. It was also reported that such indigestible compounds could act as growth inhibitors (Orinda et al., 2017). On the other hand, a high level of crude protein when associated to an unbalanced diet, could also reduce the growth rate as crickets spend a lot of energy excreting the excess of protein in the form of ammonia and uric acid (Orinda et al., 2017). The high mortality recorded in GM and BG support these results.

In this trial, higher survival, shorter development time, higher individual final weight, higher cricket yield and higher FCE were recorded in HF and MD treatments compared to other substrates. It could be speculated that these diets are well balanced for crickets, from a protein and digestible carbohydrate point of view. Digestible carbohydrate provides a promptly source of energy for growth and metabolic functions.

The composition of the diet also influenced the final cricket composition which was investigated only on HF and MD reared crickets. It is known that protein, fat and carbohydrate content in the diet are major factors influencing the composition of the cricket (Oonincx et al., 2015; Ssepuuya et al., 2021). Some authors reported that high protein content in the diet is followed by high protein content in the crickets (Bawa et al., 2020; Oonincx et al., 2015). However, in our study the protein content in cricket meal reared on HF diet and MD was similar, despite the different protein level in the diet (lower for HF (16.03\%) vs MD (26.31\%)) suggesting that the crude protein content is more species dependent rather than substrate dependent. The protein content in cricket meals found in our study was in line with Bawa et al. (2020) and Oonincx et al. (2015). We could suppose that HF, being a compound diet for laying hens, also contained vitamins, minerals and synthetic amino acids. It was then a high performant diet even having a lower crude protein content compare to MD. Concerning lipid composition, it is known that fat content influences the final composition of the edible insects. Our results are in line with literature as the major difference, even if not significant from a statistical point of view, in the proximate composition was observed in the lipid content (HF: 15.66\%; MD: 21.40\%) that followed the highest ether extract content of MD substrate. Future studies should focus on the composition of the growing substrates that affect the cricket meal: in particular, amino and fatty acids composition, as well as other macro and micro nutrient content of the diets must be considered in relation to their influence on insect growth, biomass production and the final composition of cricket meal for human use. 
The results of microbiological analyses are in line with previously published studies (Caparros Megido et al., 2017; Fernandez-Cassi et al., 2018; Klunder et al., 2012; Vandeweyer et al., 2017). Insect meal was characterised by high total microbial counts, but the identification of low E. coli counts suggested a different microbial composition if compared with other animal-based products. Moulds and yeasts were high in both substrate and cricket meal despite the low water activity of the final products. High production standards need to be followed in order to reduce existing contamination. Currently, there are no safety criteria on insects as food and some Authors suggested the possibility to use criteria available for minced meat (Caparros Megido et al., 2017) according to European Commission Regulation 1441/2007, but matrices are very different.

An interesting microbial parameter that needs to be taken into account is $B$. cereus which was isolated in high counts in substrate but not on powders, differently from other studies (Fasolato et al., 2018). B. cereus sensu latu group, which was counted through the applied ISO method, is not necessarily a pathogen because it comprises several species. However, some members of this group can produce toxins able to cause disease in human after ingestion. Both, the bacterial spores and the emetic toxin, are thermostable and need to be carefully considered along the edible insect food chain (Ceuppens et al., 2013; Stenfors et al., 2008). In relation to the heavy metal presence, which was very low in the analysed cricket meals, in the lack of specific legislative limits for the present foodstuffs, it is not possible to define compliance. However, the contamination level in crickets reared on the two experimental substrates do not raise safety concerns for potential consumers. The investigation of microbial composition of insects as novel food is of high importance to identify potential safety concern. In particular, data on microbiological aspects should be obtained not only for each insect species proposed for human consumption but also for each insect-substrate pair, as substrate is the main contributor for insects' microbiota.

\section{Conclusions}

In conclusion, the agro-industrial by-products tested unprocessed in this study did not show their suitability to support an optimal cricket growth and development, a part maize distiller, also if they represent a good starting point for further studies on the sustainability of the production of $A$. domesticus as human food. Nutritious ingredients essentials for the growth and development of the crickets were lacking. For examples, in the present study the influence of macronutrient and vitamins in the diet on the growth performance and the biomass production of the crickets was not consider, also if it is known that their content can influence the final biomass. Further studies should focus on the formulation of mix diets including a certain percentage of organic low-valuable organic matter in order to reduce environmental rearing costs and valorise the by-products otherwise not use, sustaining the circular economy.

\section{Acknowledgements}

This research was funded by CARIPLO Foundation within the Project 'Modello Allevamento di Insetti Commestibili - MAIC'.

\section{Conflict of interest}

The authors declare no conflict of interest.

\section{References}

Alexander, R.D. and Otte, D., 1967. Cannibalism during copulation in the brown bush cricket, Hapithus agitator (Gryllidae). Florida Entomologist 50: 79-89.

Association of Official Analytical Chemists (AOAC), 2000. Official methods of analysis, $16^{\text {th }}$ edition. AOAC International, Gaithersburg, MD, USA.

Association of Official Analytical Chemists (AOAC), 2003. Official methods of analysis, $17^{\text {th }}$ edition. AOAC International, Gaithersburg, MD, USA.

Bava, L., Jucker, C., Gislon, G., Lupi, D., Savoldelli, S., Zucali, M. and Colombini, S., 2019. Rearing of Hermetia illucens on different organic by-products: influence on growth, waste reduction, and environmental impact. Animals 9(6): 289. https://doi.org/10.3390/ ani9060289

Bawa, M., Songsermpong, S., Kaewtapee, C. and Chanput, W., 2020. Effect of diet on the growth performance, feed conversion, and nutrient content of the house cricket. Journal of Insect Science 20(2): 10. https://doi.org/10.1093/jisesa/ieaa014

Caparros Megido, R., Desmedt, S., Blecker, C., Béra, F., Haubruge, É., Alabi, T. and Francis, F., 2017. Microbiological load of edible insects found in Belgium. Insects 8(1): 12. https://doi.org/10.3390/ insects 8010012

Cappellozza, S., Leonardi, M.G., Savoldelli, S., Carminati, D., Rizzolo, A., Cortellino, G., Terova, G., Moretto, E., Badaile, E., Saviane, A., Bruno, D., Bonelli, M., Caccia, S., Casartelli, M. and Tettamanti, G., 2019. A first attempt to produce proteins from insects by means of a circular economy. Animals 9(5): 278. https://doi.org/10.3390/ ani9050278

Ceuppens, S., Boon, N. and Uyttendaele, M., 2013. Diversity of Bacillus cereus group strains is reflected in their broad range of pathogenicity and diverse ecological lifestyles. FEMS Microbiology Ecology 84.(3): 433-450.

Collavo, A., Glew, R.H., Huang, Y.S., Chuang, L.T., Bosse, R. and Paoletti, M.G., 2005. House cricket small-scale farming. In: Paoletti, M.G. (ed.) Ecological implications of minilivestock: potential of insects, rodents, frogs and snails. Science Publishers Inc., Enfield, NH, USA, pp. 515-540. 
EFSA Panel on Nutrition, Novel Foods and Food Allergens (NDA), Turck, D., Castenmiller, J., De Henauw, S., Hirsch-Ernst, K. I., Kearney, J., Maciuk, A., Mangelsdorf, I., McArdle, H.J., Naska, A., Pelaez, C., Pentieva, K., Siani, A., Thies, F., Tsabouri, S., Vinceti, M., Cubadda, F., Frenzel, T., Heinonen, M., Marchelli, R., NeuhäuserBerthold, M., Poulsen, M., Maradona, M.P., Schlatter, J.R., Van Loveren, H., Ververis, E. and Knutsen, H.K., 2021a. Safety of dried yellow mealworm (Tenebrio molitor larva) as a novel food pursuant to Regulation (EU) 2015/2283. EFSA Journal 19(1): e06343. http:// doi.org/10.2903/j.efsa.2021.6343

EFSA Panel on Nutrition, Novel Foods and Food Allergens (NDA), Turck, D., Bohn, T., Castenmiller, J., De Henauw, S., Hirsch-Ernst, K.I., Maciuk, A., Mangelsdorf, I., McArdle, H.J., Naska, A., Pelaez, C., Pentieva, K., Siani, A., Thies, F., Tsabouri, S., Vinceti, M., Cubadda, F., Frenzel, T., Heinonen, M., Marchelli, R., Neuhäuser-Berthold, M., Poulsen, M., Maradona, M.P., Schlatter, J.R., Van Loveren, H., Goumperis, T. and Knutsen, H.K., 2021b. Safety of frozen and dried formulations from whole house crickets (Acheta domesticus) as a novel food pursuant to Regulation (EU) 2015/2283. EFSA Journal 19(8): e06779. https://doi.org/10.2903/j.efsa.2021.6779

European Union (EU), 2017. Regulation (EU) 2017/1017 of 15 June 2017 amending Regulation (EU) No 68/2013 on the Catalogue of feed materials. Official Journal of the European Union L 159: 48119. http://data.europa.eu/eli/reg/2017/1017/oj

Fasolato, L., Cardazzo, B., Carraro, L., Fontana, F., Novelli, E. and Balzan, S., 2018. Edible processed insects from e-commerce: food safety with a focus on the Bacillus cereus group. Food Microbiology 76: 296-303. https://doi.org/10.1016/j.fm.2018.06.008

Fernandez-Cassi, X., Supeanu, A., Jansson, A., Boqvist, S. and Vagsholm, I., 2018. Novel foods: a risk profile for the house cricket (Acheta domesticus). EFSA Journal 16(S1): e16082. https://doi. org/10.2903/j.efsa.2018.e16082

Fernandez-Cassi, X., Supeanu, A., Vaga, M., Jansson, A., Boqvist, S. and Vagsholm, I., 2019. The house cricket (Acheta domesticus) as a novel food: a risk profile. Journal of Insects as Food and Feed 5(2): 137-157. https://doi.org/10.3920/JIFF2018.0021

Fowles, T.M. and Nansen, C., 2020. Insect-based bioconversion: value from food waste. In: Närvänen, E., Mesiranta, N., Mattila, M. and Heikkinen, A. (eds.) Food waste management. Palgrave Macmillan, Cham, Switzerland, pp. 321-346. https://doi.org/10.1007/978-3030-20561-4_12

Galassi, G., Jucker, C., Parma, P., Lupi, D., Crovetto, G.M., Savoldelli, S. and Colombini, S., 2021. Impact of agro-industrial byproducts on bioconversion, chemical composition, in vitro digestibility, and microbiota of the black soldier fly (Diptera: Stratiomyidae) larvae. Journal of Insect Science 21(1): 8. https://doi.org/10.1093/ jisesa/ieaa148

Gasco, L., Biancarosa, I. and Liland, N.S., 2020. From waste to feed: a review of recent knowledge on insects as producers of protein and fat for animal feeds. Current Opinion in Green and Sustainable Chemistry 23: 67-79. https://doi.org/10.1016/j.cogsc.2020.03.003

Govorushko, S., 2019. Global status of insects as food and feed source: a review. Trends in Food Science \& Technology 91: 436-445. https:// doi.org/10.1016/j.tifs.2019.07.032
Harsányi, E., Kovács, C.J.E., Huzsvai, L., Pintér, R., Fekete, G., Varga, Z.I., Aleksza, L. and Gyuricza, C., 2020. Evaluation of organic wastes as substrates for rearing Zophobas morio, Tenebrio molitor, and Acheta domesticus larvae as alternative feed supplements. Insects 11(9): 604. https://doi.org/10.3390/insects11090604

Janssen, R.H., Vincken, J.P., Van den Broek, L.A.M., Fogliano, V. and Lakemond, C.M.M., 2017. Nitrogen-to-protein conversion factors for three edible insects: Tenebrio molitor, Alphitobius diaperinus, and Hermetia illucens. Journal of Agricultural and Food Chemistry 65(11): 2275-2278. https://doi.org/10.1021/acs.jafc.7b00471

Jensen, N.H. and Lieberoth, A., 2019. We will eat disgusting foods together - evidence of the normative basis of Western entomophagydisgust from an insect tasting. Food Quality and Preference 72: 109115. https://doi.org/10.1016/j.foodqual.2018.08.012

Jucker, C., Leonardi, M.G., Rigamonti, I., Lupi, D. and Savoldelli, S., 2019. Brewery's waste streams as a valuable substrate for black soldier fly Hermetia illucens (Diptera: Stratiomyidae). Journal of Entomological and Acarological Research 51(3): 87-94. https:// doi.org/10.4081/jear.2019.8876

Kieruzel, M. and Chmurzynski, J., 1987. Behaviour of food and water deprived housecricket, Acheta domesticus (L.). Polskie Pismo Entomologiczaae 57: 645-656.

Klunder, H.C., Wolkers-Rooijackers, J., Korpela, J.M. and Nout, M.J.R., 2012. Microbiological aspects of processing and storage of edible insects. Food Control 26(2): 628-631. https://doi.org/10.1016/j. foodcont.2012.02.013

Kulma, M., Tůmová, V., Fialová, A. and Kourimská, L., 2020. Insect consumption in the Czech Republic: what the eye does not see, the heart does not grieve over. Journal of Insects as Food and Feed 6(5): 525-535. https://doi.org/10.3920/JIFF2020.0020

Laureati, M., Proserpio, C., Jucker, C. and Savoldelli, S., 2016. New sustainable protein sources: Italian consumers' willingness to adopt insects as feed and food. Italian Journal of Food Science 28: 652-668 https://doi.org/10.14674/1120-1770/ijfs.v476

Lundy, M.E. and Parrella, M.P., 2015. Crickets are not a free lunch: protein capture from scalable organic side-streams via high-density populations of Acheta domesticus. PLoS ONE 10(4): e0118785. https://doi.org/10.1371/journal.pone.0118785

Mancini, S., Moruzzo, R., Riccioli, F. and Paci, G., 2019. European consumers' readiness to adopt insects as food. A review. Food Research International 122: 661-678. https://doi.org/10.1016/j. foodres.2019.01.041

Morales-Ramos, J.A., Rojas, M.G. and Dossey, A.T., 2018. Agedependent food utilisation of Acheta domesticus (Orthoptera: Gryllidae) in small groups at two temperatures. Journal of Insects as Food and Feed 4(1): 51-60. https://doi.org/10.3920/JIFF2017.0062 Morales-Ramos, J.A., Rojas, M.G., Dossey, A.T. and Berhow, M., 2020b. Self-selection of food ingredients and agricultural by-products by the house cricket, Acheta domesticus (Orthoptera: Gryllidae): a holistic approach to develop optimized diets. PLoS ONE 15(1): e0227400. https://doi.org/10.1371/journal.pone.0227400

Morales-Ramos, J.A., Rojas, M.G., Kelstrup, H.C. and Emery, V., 2020a. Self-selection of agricultural by-products and food ingredients by Tenebrio molitor (Coleoptera: Tenebrionidae) and impact on food utilization and nutrient intake. Insects 11(12): 827. https://doi. org/10.3390/insects11120827 
Ng'ang'a, J., Fombong, T.F., Kiiru, S., Kipkoech, C. and Kinyuru, J., 2021. Food safety concerns in edible grasshoppers: a review of microbiological and heavy metal hazards. International Journal of Tropical Insect Science 41: 2103-2111. https://doi.org/10.1007/ s42690-020-00372-9

Oonincx, D.G., Van Broekhoven, S., Van Huis, A. and Van Loon, J.J., 2015. Feed conversion, survival and development, and composition of four insect species on diets composed of food by-products. PLoS ONE 10: e0144601. https://doi.org/10.1371/journal.pone.0144601

Ordoñez-Araque, R. and Egas-Montenegro, E., 2021. Edible insects: a food alternative for the sustainable development of the planet. International Journal of Gastronomy and Food Science 23: 100304. https://doi.org/10.1016/j.ijgfs.2021.100304

Orinda, M.A., Mosi, R.O., Ayieko, M.A. and Amimo, F.A., 2017. Growth performance of common house cricket (Acheta domesticus) and field cricket (Gryllus bimaculatus) crickets fed on agro-byproducts. Journal of Entomology and Zoology Studies 5(6): 1664-1668.

Pastell, H., Mellberg, S., Ritvanen, T., Raatikainen, M., Mykkänen, S., Niemi, J., Latomäki, I. and Wirtanen, G., 2021. how does locally produced feed affect the chemical composition of reared house crickets (Acheta domesticus)? ACS Food Science \& Technology 1(4): 625-635. https://doi.org/10.1021/acsfoodscitech.0c00083

Patton, R.L., 1967. Oligidic Diets for Acheta domesticus (Orthoptera: Gryllidae). Annals of the Entomological Society of America 60(6): 1238-1242. https://doi.org/10.1093/aesa/60.6.1238

Pinotti, L., Giromini, C., Ottoboni, M., Tretola, M. and Marchis, D., 2019. Review: insects and former foodstuffs for upgrading food waste biomasses/ streams to feed ingredients for farm animals. Animal 13(7): 1365-1375. https://doi.org/10.1017/S1751731118003622

Pippinato, L., Gasco, L., Di Vita, G. and Mancuso, T., 2020. Current scenario in the European edible-insect industry: a preliminary study. Journal of Insects as Food and Feed 6: 371-381. https://doi. org/10.3920/JIFF2020.0008
Simpson, S.J., Sword, G.A., Lorch, P.D. and Couzin, I.D., 2006. Cannibal crickets on a forced march for protein and salt. Proceedings of the National Academy of Sciences 103(11): 4152-4156. https://doi. org/10.1073/pnas.0508915103

Smetana, S., Palanisamy, M., Mathys, A. and Heinz, V., 2016. Sustainability of insect use for feed and food: life cycle assessment perspective. Journal of Cleaner Production 137: 741-751. https:// doi.org/10.1016/j.jclepro.2016.07.148

Sorjonen, J.M., Valtonen, A., Hirvisalo, E., Karhapää, M., Lehtovaara, V.J., Lindgren, J., Marnila, P., Mooney, P., Mäki, M., Siljander-Rasi, H., Tapio, M., Tuiskula-Haavisto, M. and Roininen, H., 2019. The plantbased by-product diets for the mass-rearing of Acheta domesticus and Gryllus bimaculatus. PLoS ONE 14(6): e0218830. https://doi. org/10.1371/journal.pone.0218830

Ssepuuya, G., Sengendo, F., Ndagire, C., Karungi, J., Fiaboe, K.K.M., Efitre, J. and Nakimbugwe, D., 2021. Effect of alternative rearing substrates and temperature on growth and development of the cricket Modicogryllus conspersus (Schaum). Journal of Insects as Food and Feed 7(2): 163-172. https://doi.org/10.3920/JIFF2020.0014 Stenfors Arnesen, L.P., Fagerlund, A. and Granum, P.E., 2008. From soil to gut: Bacillus cereus and its food poisoning toxins. FEMS Microbiology Reviews 32(4): 579-606. https://doi.org/10.1111/ j.1574-6976.2008.00112.x

Van Huis, A. and Oonincx, D.G., 2017. The environmental sustainability of insects as food and feed. A review. Agronomy for Sustainable Development 37(5): 43. https://doi.org/10.1007/s13593-017-0452-8

Van Huis, A., 2013. Potential of insects as food and feed in assuring food security. Annual Review of Entomology 58: 563-583.

Vandeweyer, D., Crauwels, S., Lievens, B. and Van Campenhout, L., 2017. Microbial counts of mealworm larvae (Tenebrio molitor) and crickets (Acheta domesticus and Gryllodes sigillatus) from different rearing companies and different production batches. International Journal of Food Microbiology 242: 13-18. https://doi.org/10.1016/j. ijfoodmicro.2016.11.007 